\title{
Aspectos Geopolíticos da Problemática Alimentar e Nutricional ${ }^{*}$
}

\author{
Bertoldo Kruse Grande de Arruda** \\ Fernando Figueira ***
}

"A luta contra a fome e sua possivel eliminação da superficie da Terra näo constitui utopia, mas um objetivo perfeitamente realizável nos limites da capacidade dos homens e das possibilidades da terra"

Josué de Castro ${ }^{1}$

* - Apresentado no Fórum Nacional sobre Desnutrição, pro. movido pela Academia Nacio. nal de Medicina e a Fundação Jocquim Nabuco. Rio de Janeiro, julho de 1987.

* - Professor Adjunto do De. partamento de Medicina Social da UFPE e membro do Conse. lho Consultivo Técnico-Cientifico do Instituto Nacional de Alimentação e Nutrição INAN.

\footnotetext{
* * - Professor Emérito da UFPE e Presidente do Instituto Materno Infantil de Pernambuco - IMIP.
}

\section{INTRODUÇÃO}

Nos dias atuais, quando o tema Nutrição ganha maiores espaços nas discussões sobre o futuro da sociedade brasileira, na perspectiva de uma nova Constituição, somos reflexivamente levados a colocar em evidência a obra pioneira de Josué de Castro ${ }^{2}$, na qual abordou de maneira clara e cora. josa a problemática alimentar, como expressão ecológica das relações do homem com o seu habitat.

A partir de então foram se intensificando e aprofundan. do os estudos, quer na área biomédica, conclusivos de que o nível de saúde de uma população depende diretamente do seu estado nutricional, quer na área sócio-econométrica, demonstrativos de que os problemas nutricionais devem ser considerados não só de natureza geocultural, mas também - e principalmente - uma resultante das incompreensões sociais e de economias defeituosas.

Desnecessário será enfatizar as implicações de um regime alimentar deficiente no crescimento e desenvolvimento do indivíduo, na saúde e no bem-estar geral. O que importa é alertar os dirigentes e sociedade para a alta prevalência das várias formas de fome em nosso país, em especial daquele tipo de fome que chamou atenção Josué de Castro - "muito mais freqüente e mais grave, em suas conseqüências numéricas, a chamada fome oculta", pois o seu conceito de fome abrange desde as deficiências latentes de determinados nutrientes até os estados manifestos de subnutrição e desnutrição. 
$A$ influência recíproca de inúmeros fatores do ambiente, máxime de determinadas condições sócio-econômicas e de certas formas de conduta, foi analisada por essa figura exponencial de nutrólogo em "Geopolítica da Fome", onde desenvolve uma "interpretação da dinâmica dos fenômenos políticos em sua realidade espacial, isto é, frente às realidades e contingências do meio natural e do meio cultural".

O que se constata, na atualidade, é uma maior ressonância da teoria da causalidade social, da preeminência daqueles fatores ambientais em relação aos aspectos biológicos, pois são os desequilibrios e desigualdades que geram e perpetuam as deficiências nutricionais. E essas disparidades existem tanto entre países, como dentro de espaços geográficos de um mesmo país, figurando neste último caso as desigualdades regionais entre o Sul e o Nordeste brasileiros.

Em que pesem os movimentos de solidariedade humana e os avanços científicos e tecnológicos, grandes contingentes populacionais defrontam-se com esses desequilibrios e desigualdades. $O$ desafio que se coloca para o Governo e a própria sociedade é a correção dessas situações deprimentes.

Infelizmente é desalentador, nestes últimos anos, o quadro que estamos vivenciando no Brasil, caracterizado por mudanças profundas na conjuntura econômico-social. $\mathrm{O}$ processo inflacionário atingiu um ritmo inusitado; o desequilíbrio da balança de pagamentos resultou numa dívida externa de mais de 110 bilhões de dólares; vive-se um clima recessivo que se traduz em retração do mercado in terno, desemprego, subemprego e contenção salarial.

Diante dessa situação inquietante foram estabelecidas estratégias para enfrentar a crise:

- em 1986, o Plano Cruzado impôs um choque à economia brasileira, ocorrendo a reversão das expectativas otimistas poucos meses depois;

- agora (1987), o Plano Bresser incorpora o que de positivo havia na experiência anterior, definindo marcos corretivos que serão implementados em três fases, iniciando-se com o congelamento geral de preços e salários.

Todavia, os ajustes para debelar a crise que essa estratégia conjuntural preconiza têm, certamente, repercussōes colaterais nas condições de vida da população. A prioridade que se pretendia dar à chamada "agricultura doméstica", voltada para o abastecimento interno, perdeu importância em relação às culturas de exportação. Assim mesmo sem competitividade nos mercados compradores externos, pois somente a soja está encontrando preços compensadores.

Este ano estamos colhendo a maior safra agrícola da história - 64 milhões de toneladas -, mas a disponibilidade in- 
terna está ameaçada pelas perdas pós-colheita, em particular a insuficiência de condições adequadas de armazenagem, e a demanda mostra-se retraida frente ao comportamento dos preços praticados a nível do merca do varejista.

Destarte, as propostas no campo de alimentação e nutrição chocam-se, inevitavelmente, com as adversidades concretas da conjuntura e as mudanças de curso da política econômica e social para contrabalançar seus efeitos.

\section{1 - OS PROBLEMAS NUTRICIONAIS}

Em um país de enormes diversidades geográficas e sociais estes problemas conjunturais contribuem, significativamente, para a coexistência de modalidades variadas de qualidade de vida, refletidas em indicadores de saúde e nutrição que compreendem desde a patologia da pobreza, característica de países subdesenvolvidos, até a patologia da riqueza, típica das sociedades mais adiantadas.

Esse mosaico de situações contrastantes visualiza-se na Tabela 1, onde constam por grandes regiōes e o Brasil como um todo, seis indicadores sociais básicos ${ }^{3}$.

Estas constatações podem ser tomadas, genericamente, como a indicação epidemiológica preliminar do nível de saúde e, ao mesmo tempo, do elenco associado de deficiên. cias nutricionais que entram na sua composição.

TABELA 1

Brasil. Indicadores Sociais por Região, 1984

\begin{tabular}{lcccccc}
\hline & $\begin{array}{c}\text { Esperança } \\
\text { de vida* }\end{array}$ & $\begin{array}{c}\text { Mortalidade } \\
\text { Infantil } \\
\text { (menos de } \\
\mathbf{1} \text { ano) } \\
(\mathbf{0} / 00)\end{array}$ & $\begin{array}{c}\text { Leitos para } \\
\text { internação** } \\
(\mathbf{p} / 1.000 \mathrm{hab})\end{array}$ & $\begin{array}{c}\text { Ligação } \\
\text { d'água na } \\
\text { rede geral }\end{array}$ & $\begin{array}{c}\text { Ligações de } \\
\text { esgoto na rede } \\
\text { geral e fossa } \\
\text { séptica } \\
(\%)\end{array}$ & $\begin{array}{c}\text { Taxa de } \\
\text { alfabetização }\end{array}$ \\
\hline NORTE & 63,6 & 74,3 & 4,6 & $79,9 * *$ & $35,2^{* * *}$ & $86,8^{* * *}$ \\
NORDESTE & 51,0 & 124,5 & 2,6 & 42,6 & 15,8 & 60,0 \\
SUDESTE & 64,4 & 71,6 & 5,3 & 81,7 & 66,0 & 86,3 \\
SUL & 67,2 & 60,9 & 5,1 & 61,7 & 48,9 & 85,7 \\
CENTRO-OESTE & 63,9 & 75,3 & 4,4 & 55,9 & 22,2 & 76,6 \\
BRASIL & 60,1 & 87,9 & 4,2 & 66,2 & 46,1 & 78,7 \\
\hline
\end{tabular}

\footnotetext{
$* 1980$

$*$ *1982

***Exclusive populaçäo rural.

Fonte : IBGE, Indicadores Sociais. Tabelas Selecionadas, vol. 2, 1984 e PNAD 1984, Brasil e Grandes Regiōes

Referência no 3.
} 
É sobremodo expressivo o tributo que representa, por exemplo, as mortes antecipadas por várias causas, entre as quais predominam as doenças infecciosas e os processos carenciais.

Considerando-se a mortalidade infantil como um in dicador sensível dessa situação, observa-se que, no Nordeste brasileiro (Tabela 2), as doenças diarréicas respondem por $35 \%$ das mortes prematuras; somando-se as infecçôes respiratórias agudas, as septicemias e a desnutrição, temos $58,8 \%$ dos óbitos de menores de 1 ano como resultantes de uma associação onde as deficiências nutritivas são a causa direta ou indireta de morte. Vale referir que esse percentual acumulado deste complexo causal destaca-se, marcadamente, do próprio quadro nacional.

Explanaremos a seguir, em seus delineamentos marcantes, aquelas situações que, dentro do amplo espectro de doenças carenciais, revestem-se, efetivamente, de interesse médico-social, que são: a desnutrição energético-protéica, a hipovitaminose $\mathrm{A}$, as anemias e o bócio.

\section{1 - Desnutrição energético-protéica - DEP}

No tocante à DEP, embora a suscetibilidade biológica seja universal, as agressōes mais freqüentes e de maior gravidade ocorrem no segmento materno.infantil ${ }^{4}$. Esta observação é pertinente, uma vez que a DEP tem importância nas populações adultas, em face das limitações que acarreta para o trabalho físico, mas sob o ponto de vista da saúde pública é o mencionado grupo populacional que polariza as atenções.

Quanto ao estado nutricional de gestantes, dados de 15 localidades do Nordeste brasileiro indicaram estaturas médias de gestantes em torno de 150 centímetros ${ }^{5}$. Resultados semelhantes foram encontrados por Pino e cols. ${ }^{6}$ entre mães de familia sem terra. Em São Paulo, Ciari Junior e cols. $^{7}$ assinalaram a ocorrência de $13,6 \%$ de gestantes com menos de $150 \mathrm{~cm}$ de altura. Cumpre referir que esses valo. res estão próximos ao ponto crítico de $147 \mathrm{~cm}$, estreitamente relacionado com o risco de baixo peso ao nascer.

Estudo realizado por Batista Filho e Amigo $^{8}$, em quatro capitais brasileiras, tomando como referencial o peso gravídico, para avaliação do estado nutricional de gestantes, encontrou uma prevalência de baixo peso máxima em Belém do Pará $(37,2 \%)$, mediana no Recife $(21,9 \%)$ e Natal $(19,6 \%)$, e mínima em São Paulo $(12,2 \%)$.

É consensual a referência de que a baixa estatura das mães e a evolução desfavorável do peso gravídico se correlacionam, freqüentemente, com o baixo peso ao nascer, seja por desnutrição intra-uterina, seja pelo risco de prematuridade. Os dados mais recentes indicam que, no Brasil, 8,5\% 
das crianças nascem com peso inferior a $2.500 \mathrm{~g}$ e no Nordeste, estima-se em $15 \%$. Na Tabela 2 podemos inferir a relevância da prematuridade na mortalidade infantil, pois $29 \%$ das mortes são devidos a causas perinatais.

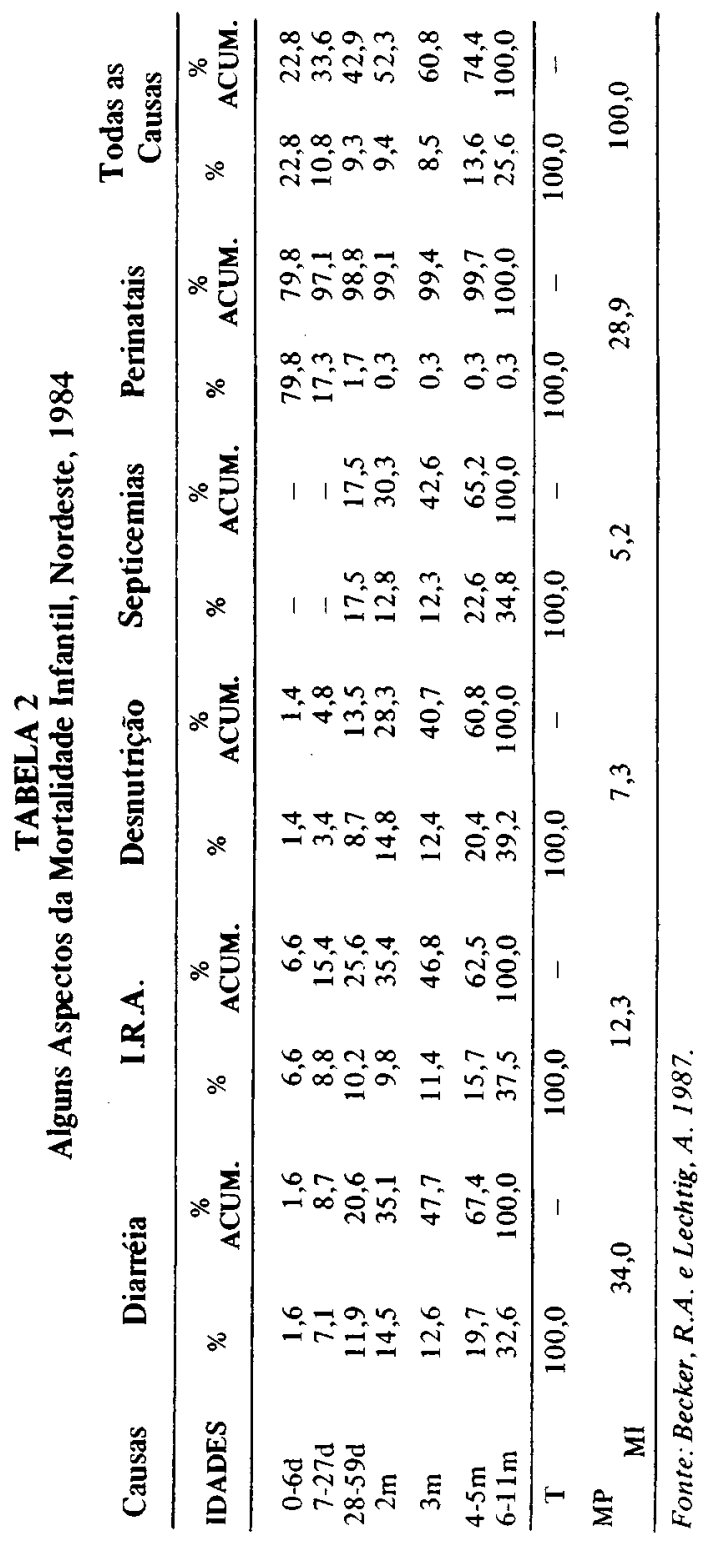


No que diz respeito à situação nutricional de crianças menores de 5 anos, o grupo vulnerável mais sensivel aos fatores ambientais, é significante o estudo comparativo que o UNICEF e a FIBGE $^{9}$ realizaram confrontando duas áreas econômica e socialmente distintas do país, o Nordeste e o Estado de São Paulo, com base em dados do ENDEF (1974/75). A prevalência acumulada das formas moderadas (grau II) e graves (grau III) de DEP é quatro vezes maior no Nordeste brasileiro; em termos de distribuição urbano/rural, as populaçōes rurais teriam um risco mais elevado $(1 / 3)$ de evoluir para estágios mais severos de desnutrição.

Em publicação recente ${ }^{10}$, Batista Filho consolidou os resultados de trabalhos efetuados após o ENDEF, em amostras de várias localidades nordestinas, os quais revelam freqüências de desnutrição de II e III graus em mais de $15 \%$ dos examinados. Trata-se sem dúvida, de uma situação nutricional bastante desfavorável.

Aliás, essa concentração de casos mais graves entre os menores de 2 anos é uma obseryação generalizada, pois os casos de DEP III praticamente desaparecem após o segundo ano de vida. Atribui-se esse fato à maior vulnerabilidade das crianças dessa faixa etária à desnutrição, onde coincidentemente prevalecem os fatores que aceleram e agravam 0 quadro carencial, como as infecções e a desidratação.

Todavia, há informes de que a ocorrência da desnutrição esteja declinando. Recentemente, a BENFAM realizou a "Pesquisa Nacional sobre Saúde Materno-Infantil e Planejamento Familiar", encontrando na amostra estudada na Região Nordeste (1208 crianças) somente $7 \%$ de desnutrição moderada $(6,2 \%)$ e grave $(0,8 \%)$, contribuindo o grupo de menores de 2 anos com $57,3 \%$ do total de casos de DII e $70 \%$ de DIII $^{11}$.

Na casuística do Projeto SIVAN (FUNDAJ/INAN), baseada na demanda de oito unidades de Saúde do Recife, os dados do ano de 1985 (35.563 crianças menores de cinco anos) revelam uma redução apreciável da desnutrição moderada $(6,8 \%)$ e grave $(1,5 \%)$, distanciando-se dos percentuais encontrados no ENDEF, e nem se observou a concentração desses casos nos dois primeiros anos ${ }^{12}$.

No município de São Paulo, Monteiro e cols. ${ }^{13}$ executaram no periodo 1984/85 uma ampla pesquisa para estabelecer as condições de saúde e nutrição da população. Os resultados foram surpreendentes: a prevalência estimada foi de 2,9\% para formas moderadas de desnutrição (DII) e nula a prevalência de formas severas (DIII). Concluem os autores que essa é uma situação privilegiada, tanto em relação ao conjunto de populaçōes do Terceiro Mundo e, igualmente, em relação ao Brasil. 
Em que pesem essas constatações animadoras, o Brasil ocupa o 32 ? lugar do Indice Internacional de Sofrimento Humano, elaborado pelo "Population Crisis Committee", com sede em Washington ${ }^{14}$, posição pouco invejável, como diz o articulista, para um país que é festejado como a oitava economia ocidental.

Ainda sobre o estado nutricional de pré-escolares, Batista Filho e cols. ${ }^{15}$ estudaram 225 crianças de familias ru. rais radicadas em 8 engenhos da Zona da Mata (zona açucareira) do Estado de Pernambuco. Utilizando a classificação de Gomez (adequação peso/idade), verificaram que apenas $30,2 \%$ das crianças seriam normais: metade apresentava estatura abaixo de -2 D. P., classificando-se na condição de nanismo. Comentam os autores: "Pode-se pensar, conclusivamente, que o atraso de crescimento ósseo, com o equilíbrio 'a posteriori' da relação peso/altura, é a característica principal da desnutrição protéico-calórica da área rural aqui estudada. Esta característica (atraso estatural) é ainda mais marcante que a encontrada em São Luiz (36\%) e cidades do interior de Pernambuco".

Ocorre, por conseguinte, já nos dois primeiros anos de vi. $\mathrm{da}$, um comprometimento intenso do programa genético de crescimento. Este alerta foi dado por Nelson Chaves quando referiu que estávamos criando, no Nordeste, uma geração de nanicos.

Nesse estudo, Batista Filho aplica à epidemiologia da nutrição o enfoque "das respostas adaptativas que se cumprem com o prejuízo da estatura, em favor de um novo equilibrio com o peso, previamente comprometido. Estas relaçōes têm sido consideradas no enfoque fisiopatológico, na conceitua. çâo de "homeostase mediata' de Marcondes".

Um outro estudo do grupo de saúde pública do Institu. to de Nutrição da UFPE ${ }^{16}$, avaliando o estado nutricional de 1257 crianças menores de seis anos, segundo a posse da terra, em áreas rurais do Estado de Pernambuco, revelou, adotando a classificação de Gomez, uma prevalência de $55,1 \%$ de desnutrição, com $11,2 \%$ de DII e $1,2 \%$ de DIII. "Com relação à posse da terra, observa-se uma tendência decrescente dos casos de desnutrição, à medida que aumen. ta o tamanho da propriedade. A categoria das familias sem terra apresenta $65 \%$ de desnutridos, contra $25 \%$ da categoria dos proprietários de 50 e mais hectares".

Em São Paulo (Ribeirão Preto) as diferenças entre níveis sócio-econômicos foram mostradas por Dutra de Oliveira e cols. ${ }^{17}$, pesquisando o estado nutricional dos filhos dos tra. balhadores volantes rurais (bóias-frias) mediante o exame de, aproximadamente, 400 crianças de nível sócio-econômico baixo e para comparação, também de 400 crianças de ni. ve sócio-econômico alto. Evidenciaram que "o peso dos me- 
ninos 'ricos' de Ribeirão Preto é bastante semelhante ao padrão de Boston, maior que a média da curva de Santo André (S. Panlo) e bem superior ao dos meninos filhos de familias de bóras-frias".

\section{2 - Hipovitaminose $\mathrm{A}$}

Os dados disponiveis ainda são insuficientes para demarcar a situação nosográfica da hipovitaminose A no Brasil, embora já se tenham localizado áreas com níveis de prevalência que a identificam como problema de saúde pública, dentro dos parâmetros estabelecidos pela OMS.

Em 1982-1983, Santos e cols. ${ }^{18}$ detectaram 1,9\% de prevalência de Mancha de Bitot em cerca de 11.000 crianças examinadas, frequêencia que é indicativa de uma situação endêmica.

No Nordeste brasileiro ${ }^{19}, 20$, nos Estados de São Pau$10^{21}$ e Minas Gerais ${ }^{22}$, foram determinados níveis sangüineos de vitamina $\mathrm{A}$ abaixo dos valores considerados normais, em mais de $15 \%$ dos examinados. Especificamente, no semi-árido nordestino, na época da estiagem, o problema emerge com as características de uma endemia e os da. dos mais dramáticos que o retratam são os do Estado da $\mathrm{Pa}$. raiba.

No estudo de Lira e cols ${ }^{23}$, em áreas rurais do Estado de Pernambuco, "os achados bioquímicos relativos à magnitude da prevalência da hipovitaminose $A$, para o total da amostra (1257 crianças menores de 6 anos), revelaram elevados percentuais de préescolares com níveis deficientes e baixos de retinol sérico. Por outro lado, não foram detectados sinais clínicos oculares, característicos desta carência".

\section{3 - Anemias}

Os vários registros existentes mostram que a prevalência da anemia nutricional ferropriva varia de 20 a $80 \%$, traduzindo um problema que deve ser considerado na relação de prioridades de saúde. Recentemente, o INAN consolidou dados produzidos entre 1982 e 1983, em 5 Estados (S. Pau1o, Pará, Minas Gerais, Pernambuco e Pararba), resultantes de estudos colaborativos envolvendo diversas universidades, os quais possibilitaram concluir que as anemias representam um problema de saúde coletiva ${ }^{24}$. Nesse sentido, são concordantes as observações de Shrimpton, no Amazonas ${ }^{25}$, de Salzano ${ }^{26}$ e Salzano e cols. ${ }^{27}, 28$, nos Estados de Pernambuco e Paraîba; de Szarfac ${ }^{29}$, em São Paulo, de Lira e cols. ${ }^{30}$ em áreas rurais e de $A r r u d a^{31}$ em áreas urbanas de Pernambuco. 
Em 1984, nos escolares de 7 a 14 anos que foram examinados para ingresso no projeto de intervenção nutricional promovido pelo INAN e a FAE no município de Axixá de Goiás, a prevalência de anemia atingiu uma proporção alarmante $-98 \%$.

\section{4 - Bócio endêmico}

A endemia bocígena foi avaliada pela SUCAM em dois inquéritos nacionais, realizados em 1955 e 1975, obtendose as prevalências de $20,6 \%$ e $14,1 \%$, respectivamente. Com base nessas duas avaliaçōes epidemiológicas ${ }^{32}$, observou-se uma redução de $6,5 \%$, sendo provável que, atualmente, tenha ocorrido uma diminuição considerável, em decorrência das medidas de profilaxia adotadas pelo INAN.

\section{2 - OS PRINCIPAIS FATORES CONDICIONANTES DO ESTADO NUTRICIONAL}

A situação nutricional do Brasil, cujos aspectos mais relevantes foram discutidos no item anterior, pode ser resumida na estimativa de que há cerca de 80 milhões de brasileiros como hospedeiros potenciais de carências nutritivas ostensivas ou, mais freqüentemente, subclínicas. Nesse universo as crianças constituem o contingente mais expressivo, as quais, em altíssimo percentual nas áreas rurais do Nordeste (aproximadamente 40\%), segundo conclusões de Batista Filho $^{33}$, "seriam classificadas na faixa de nanismo, com atraso marcante de estatura já nos 2 primeiros anos de vida".

Émbora se saiba o papel que desempenha a carga genética na determinação do crescimento e desenvolvimento, é inegável que os fatores decisivos na modulação da forma e do grau desse desenvolvimento são os relacionados ao am. biente, isto é, de natureza exógena, que continuamente interagem com os de origem endógena do indivíduo. $\mathrm{E}$ dentre as privações ambientais, a carência alimentar é a mais fundamental.

Isto não quer dizer que o ambiente pode criar uma qualidade diversa da que existe, latentemente, na constituição genética. Porém é nesse constante interagir frente aos fenômenos ambientais, que a criança elabora formas cada vez mais aperfeiçoadas de equilíbrio com o seu habitat. Então, o crescimento físico e a maturação da criança em idade pré-escolar variam em função da alimentação.

Daí ser indispensável a compreensão exata da natureza e dimensão desses condicionantes ambientais, com vistas a controlá-los e organizá-los, de modo que contribuam para que as crianças se tornem adultos equilibrados e utilizem o máximo de suas potencialidades. 
Assim, o mais essencial é garantit um bom estado de nutrição. A nivel biológico, esse processo ficaria restrito ao binômio consumo de alimentos/aproveitamento metabólico de nutrientes. Em uma instância mais genérica, ecológica, consideram-se os: pectos geopolíticos, os fatores determinantes da produção e disponibilidade de alimentos, que representa o enfoque analítico do nível macroeconômico, e as variáveis que interferem no consumo alimentar e utilização biológica de nutrientes, que configura o enfoque do nivel microeconômico ou familiar.

\section{1 - 0 enfoque macroeconômico: produção e disponibilidade de alimentos}

O grande dilema social do sistema agropecuário é a disposição dual da economia rural brasileira: um setor atrasado e empobrecido respondendo ao mercado interno, e um setor avançado e rico voltado aos mercados internacionais e ao Proálcool.

Este descompasso tornou-se evidente a partir da década de 70. Antes, em termos de produção por habitantes, era equilibrado o crescimento dos principais produtos de mercado interno e os exportáveis. Tal quadro modificou-se com a modernização da agricultura, à conta da associação de alguns fatores analisados por Homem de Melo ${ }^{34}$, ${ }^{35}$, resultando numa mudança substancial na composição do produto brasileiro.

$\mathrm{Na}$ Tabela 3 vemos a evolução, no periodo $1975 / 86$, da produção "per capita" dos principais produtos de exportação: café, cacau, soja, laranja e cana-de-açúcar. É um desempenho extremamente favorável, típico da grande propriedade, que explora a agricultura como uma empresa capitalista. Para isso dispõe de aplicações de capital in tensivo, portanto, de recursos tecnológicos modernos, crédito facilitado e mecanismos de defesa contra as oscilações maiores do mercado.

É bem contrastante a situação demonstrada na Tabela 4, onde visualiza-se nesse mesmo periodo, o perfil da produção "per capita" dos principais produtos básicos: arroz, feijão, milho, mandioca e trigo. $\dot{A}$ exceção deste último, evidencia-se uma evolução insatisfatória. Isto porque o sistema produtivo da agricultura dita "doméstica" é precário, pois está em grande parte, sob a responsabilidade de pequenos proprietários com menos de 50 hectares e de agricultores sem terra. Uma expressiva maioria deles não dispõe de capital próprio, recorrem à mão-de-obra intensiva da família, lutam com dificuldade para obter crédito, a tecnologia que utilizam é inadequada e em virtude da baixa produtividade, o custo da produção é relativamente elevado. Outrossim, 
sem poder de barganha, esses pequenos produtores rurais tornam-se presa fácil dos chamados atravessadores, que formam os elos intermediários da cadeia de comercializa. ção.

TABELA 3

Produção "Per Capita" de Alimentos no Brasil - 1975/1986

( $\mathrm{Kg} /$ habitante/ano)

\begin{tabular}{lcrrrr}
\hline Ano & Laranja & Soja & Café & Cacau & Cana-de-açúcar \\
\hline 1975 & 58,9 & 94,1 & 23,7 & 2,6 & 854,2 \\
1976 & 65,1 & 104,2 & 6,8 & 2,1 & 936,9 \\
1977 & 63,3 & 113,3 & 17,2 & 2,2 & $1.060,7$ \\
1978 & 67,2 & 84,2 & 21,8 & 2,4 & $1.109,6$ \\
1979 & 70,6 & 88,2 & 22,3 & 2,8 & $1.160,7$ \\
1980 & 89,8 & 127,3 & 17,5 & 2,6 & $1.225,6$ \\
1981 & 91,8 & 122,2 & 32,8 & 2,7 & $1.256,8$ \\
1982 & 91,4 & 102,4 & 15,1 & 2,8 & $1.470,8$ \\
1983 & 90,3 & 112,4 & 25,8 & 2,9 & $1.664,8$ \\
1984 & 97,6 & 117,1 & 21,4 & 2,5 & $1.675,9$ \\
1985 & 104,9 & 134,8 & 28,2 & 3,2 & $1.823,5$ \\
1986 & 96,2 & 96,3 & 14,0 & 3,3 & $1.722,1$ \\
\hline
\end{tabular}

Fonte: SUPLAN/FIBGE

$* 1 \mathrm{~kg}=5$ laranjas ao natural

TABELA 4

Produçâo "Per Capita" de Alimentos no Brasil - 1975/1986

( $\mathrm{Kg} /$ habitante/ano)

\begin{tabular}{llcccc}
\hline Ano & Arroz & Feijão & Milho & Mandioca & Trigo \\
\hline 1975 & 74,0 & 21,7 & 155,4 & 284,4 & 38,9 \\
1976 & 90,6 & 17,1 & 164,8 & 236,2 & 59,4 \\
1977 & 81,5 & 20,7 & 174,4 & 234,8 & 42,5 \\
1978 & 64,4 & 19,4 & 117,4 & 224,8 & 62,0 \\
1979 & 65,4 & 18,9 & 140,5 & 215,0 & 56,7 \\
1980 & 81,9 & 16,5 & 171,1 & 196,6 & 62,7 \\
1981 & 62,2 & 19,3 & 171,6 & 197,9 & 49,5 \\
1982 & 77,5 & 22,7 & 174,7 & 191,6 & 49,0 \\
1983 & 59,7 & 12,2 & 144,3 & 168,4 & 63,3 \\
1984 & 68,0 & 20,0 & 159,5 & 160,4 & 67,4 \\
1985 & 66,6 & 18,8 & 162,4 & 170,6 & 74,5 \\
1986 & 75,1 & 16,0 & 148,1 & 184,4 & 57,5 \\
\hline
\end{tabular}

Fonte: FIBGE e CACEX. 
Daí as limitaçôes do abastecimento, pois esses pequenos produtores são responsáveis por cerca de $50 \%$ da produção de alimentos essenciais.

A presença dos pequenos produtores e assalariados rurais converte-se parcialmente, para os grandes latifúndios, numa necessidade. A agricultura brasileira vive dentro do complexo latifúndio (quase sempre improdutivo) - minifúndio (geralmente exaurido). De um lado, a concentração de terra, dos meios de produção e do poder econômico, político e social nas mãos de poucos, que constituem o centro do sistema; do outro, o crescimen to do número de minifúndios, com insuficientes recursos e poder, cujo principal papel é o de fornecer mão-de-obra barata ao latifúndio e/ou à empresa rural.

Em resumo, o modelo de desenvolvimento agrícola vem criando:

- altos índices de terra inexplorada, como reserva de va. lor, em detrimento da produçāo agrícola;

- forte alteração na composição da força de trabalho, provocando o assalariamento do homem do campo; $e$

- alto contingente de famílias rurais desagregadas da terra, agravando o processo migratório campo-cidade.

É o panorama de um país que tem plenas condições de ser auto-suficiente na produçẫo de alimentos básicos, uma vez que os principais fatores de produção estão disponiveis, entre os quais podemos citar:

- 680 milhões de hectares agricultáveis, dos quais são utilizados apenas 95 milhōes;

- 530.691 tratores em 1980, quando existiam em 1960 somente 61.234;

-4.066 .000 toneladas de fertilizantes consumidas em 1980, enquanto em 1960 esse consumo só atingiu 305.000 toneladas.

Em suma, ainda há bastante área cultivável e o mercado brasileiro dispõe de tecnologia, equipamentos e in sumos modernos, demonstrando que o setor agrícola modernizouse a taxas elevadas.

Todavia, refere Buainain ${ }^{36}$ que, "associada a esse pro. cesso de modernização, ocorreu a concentração da propriedade da terra e, simultaneamente, cresceu a área de terra cultivável não aproveitada". Em 1984, o 1 ? Plano Nacional de Reforma Agrária estimou que $41 \%$ da área aproveitável dos latifúndios não era utilizada.

Surgem duas indagaçōes:

1 - a atual estrutura agrária tem agilidade para responder às demandas do mercado?

2 - a proposta da reforma agrária é um instrumento capaz de expandir a produção de alimentos no país? 
No primeiro caso, as dúvidas foram suscitadas pela queda do dinamismo da agricultura que se sucedeu ao acelerado crescimento na década passada. A produção total de grãos estagnou-se nos cinqüenta milhões de toneladas anuais, enquanto os preços dos alimentos dobravam, em termos reais, entre 1971 e 1980.

Em que pesem algumas opiniões, de que a crise da produção de alimentos estaria estruturalmente ligada à "modernização conservadora" ocorrida ao longo dos anos 70 , Buainain questiona a vinculação necessária entre reforma agrária e crise agrícola e responde àquela pergunta afirmando que a estrutura agrária atual atende às demandas do mercado, desde que elas existam.

Seu argumento mais forte é o desempenho da safra de 1986 e da safra do Cruzado: "em 1986, mesmo sofrendo o efeito da estiagem, a área colhida de arroz, feijão, mandioca, milho e batata foi superior à área colhida em 1985". Esse dinamismo da oferta agrícola constata-se nas estimativas da FIBGE e da Comissão de Financiamento da Produção do MA, em março deste ano: um acréscimo de $12 \%$ em relação à safra de 1985 e de $22,5 \%$ em relação a 1986. Alcançaríamos, este ano, uma supersafra de 64 milhões de toneladas, não fossem as perdas em torno de 4 milhões de toneladas, devidas à quebra da safra nordestina, à redução da área plantada do trigo e à queda na produtividade da cultura do milho na região centro-sul. Convém referir que os maiores acréscimos de áreas cultivadas registraram-se para os produtos considerados básicos: arroz, feijão, milho e batata.

Este resultado supera o previsto no Plano de Metas: politica agrícola (10 PND-NR), revelando a inexistência de rigidez da oferta agrícola, isto é, de incapacidade estrutural de expandir a produção. A explicação deve ser buscada no baixo nível de renda da populaçẫo brasileira, aspecto há algum tempo levantado por Kertész ${ }^{37}$. Por outro lado, não se pode exigir da grande propriedade que produza alimentos para o mercado interno, se há preços mais vantajosos e, até certo ponto, mais estáveis no mercado in ternacional. Sem preços atrativos é impossivel reorientar vocações agrícolas.

Vale salientar que a política agricola elaborada o ano passado foi bem concebida, uma vez que se propunha a corrigir as distorçōes apontadas entre a produção no seg. mento de exportação e o crescimento da produção de alimentos básicos, mediante um conjunto sincronizado de inștrumentos de política (crédito rural, preços mínimos, estoques reguladores), de um elenco de obras de infra-estrutura (armazenagem, transporte e irrigação), e de atividades complementares no campo da extensão rural e da pesquisa 
agropecuária, prevendo intervençōes diferenciadas regionalmente.

Porém, essa alegria de uma política setorial equilibrada durou pouco. Não porque sejam in conciliáveis o dinamismo da agricultura doméstica com a dos produtos exportáveis. $O$ que ocorreu, conforme referimos nas considerações introdutórias desse trabalho, foi o desvirtuamento pelo Governo de sua politica para o setor, dando novamente um tratamento preferencial aos produtos exportáveis. Apesar desses percalços ainda temos um excedente de 619 mil toneladas de arroz e de 2,2 milhões de toneladas de milho, verificando-se um déficit quanto ao feijão, pela influência de fatores climáticos na época da colheita. Diante desse excesso de grãos o governo enfrenta a incapacidade de armazená-lo adequadamente e para as sobras restam duas alternativas: uma seria exportá-los, que é uma possibilidade remota em face dos preços internos do milho e do arroz serem, respectivamente, $80 \%$ e $50 \%$ mais caros do que no mercado externo; outra, é distribuí-los com as populações carentes, que é a alternativa mais provável. Todavia, poderá ter efeitos desfavoráveis se não observar princípios e critérios universalmente aceitos, em especial caso não seja associada às açōes básicas de saúde. Esta proposta foi objeto de análise pelo Conselho Técnico-Cientifico do INAN que, por intermédio do Ministro da Saúde, levou ao Presidente da República o seu posicionamento em relação às medidas de curto prazo para enfrentar - problema alimentar do país, desaconselhando a criação de novos programas e recomendando a expansão, fortalecimento e aperfeiçoamento dos existentes, sem descurar a necessidade de mudanças na política econômica que garantam niveis satisfatórios de emprego e salários.

Vejamos o segundo questionamento: a reforma agrária e a produção de alimentos, isto é, vincular a realização da reforma à necessidade de expandir a produção de gêneros básicos.

Com a abertura democrática, tomou novo alento o movimento pela transformação da estrutura agrária do país. Admitem alguns especialistas que seria o remédio para males como o elevado índice migratório na direção campo/cidade, para aumentar a produção de alimentos e melhorar a renda da população rural. Essa vinculação é bastante defendida e foi tema dominante na recente Conferềncia Nacional de Alimentação e Nutrição, realizada em Brasília. Contudo, no Seminário sobre Economia e Nutrição, promovido pelo INAN e a UNB, posteriormente à citada Conferência, Buainain ${ }^{36}$ alinhou argumentos mostrando ser enganosa a expectativa de que a reforma agrária venha a contribuir substancialmente para a disponibilidade interna de alimentos. No seu entender, "é preciso defender a reforma agrária 
como uma necessidade social. Sua eficácia do ponto de vista econômico e social dependerá de como ela for implantada. Se o modelo seguido insistir em enfatizar a pequena produção, as perspectivas não são nada promissoras, como o demonstram as experiências de reformas na América Latina".

Realmente, ainda é expressiva a participação dos pequenos produtores na producão de alimentos básicos. mas. ultimamente os estabelecimentos de mais de 100 ha vêm participando significativamente.

Essa inclinação decorreu da maior dinamicidade do mercado de alimentos básicos, pois a já aludida supersafra foi estimulada por uma maior capacidade aquisitiva da população. Daí a conclusão desse expositor: "mantida a atual distribuição de renda, o baixo poder de compra da população, a mesma política social do Governo em relação à questão da fome, enfim, mantido o baixo dinamismo do mercado de alimentos básicos, pretender vincular os produtores beneficiados pela Reforma Agrária à produção de alimentos bási. cos é apostar no fracasso dos objetivos da reforma".

Infelizmente, por melhores que sejam as intenções do Governo nesse campo, chegando a formular metas ambiciosas, segundo declaraçōes do Ministro Marcos Freire, da Reforma Agrária, não foram atingidas $5 \%$ de tais metas.

Do lado da oferta o que se impõe é definir prioridades nos instrumentos de política agrícola que permitam alterar o perfil da safra, em benefício de uma maior participação dos produtos básicos. $\hat{\mathrm{E}}$ evitar mudanças bruscas na economia, as quais são incompatíveis com uma fácil adaptaçāo à sazonalidade agrícola. E tornar os insumos acessíveis e os mercados confiáveis, sem a ocorrência da instabilidade de preços. É promover a participação governamental no processo e estimular a organização dos produtores, sem a permamente tutela do Estado.

Esta proposta reformista está ganhando mais adeptos porque a questão agrária, em decorrência do fluxo migra. tório, tem contribuído para agravar a questão urbana, ocasionando malefícios, hoje tão propalados, discutidos e preocupantes: formação de favelas, problemas de delinqüência, abandono de menores, prostituição, fome, desemprego e subemprego, etc. Em síntese - marginalização de vastas camadas sociais urbanas e criação de bolsões de pobreza junto às grandes metrópoles.

\section{2 - 0 enfoque microeconômico: consumo alimentar e aproveitamento biológico de nutrientes}

Em uma instância final, o consumo alimentar de uma população depende dos hábitos culturais prevalecentes, que in. fluem na seleção dos produtos preferidos, e preponderan- 
temente do poder aquisitivo da família, o qual é determinativo do que deve ser comprado e em que proporções.

No tocante ao papel dos hábitos culturais, procedemos revisão ${ }^{38}$ elucidativa de que sua influência não é decisiva no estado nutricional, consoante se proclamava como observação antropológica, em face das restrições ocasionadas por tabus e crenças, ou rejeição de alimentos por apreciaçōes culturais errôneas.

Conclusivamente, os estudos permitem estabelecer os seguintes balizamentos:

a) apesar das diverșidades dos hábitos alimentares entre diferentes povos, culturas e estratos sociais, em distintos períodos históricos, o valor nutricional da dieta, que é fundamentalmente o que importa, resulta das possibilidades econômicas de acesso aos alimentos;

b) é o nível econômico da família o principal condicionante do valor nutritivo da dieta, mais do que o perfil qualitativo da alimentação selecionada pela cultura da população.

Portanto, são muitas as evidências de que o valor da dieta e, igualmente, o consumo alimentar, têm a renda "per capita" como fator decisivo na sua doterminação. Os estu-

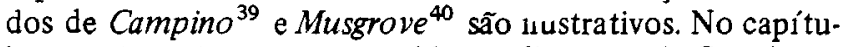
lo anterior, vimos que o problema alimentar do Brasil não pode ser explicado, convincentemente, pelas distorções da estrutura agrária e conseqüentes desequilíbrios na produção e disponibilidade de alimentos. A explicação mais plausível estaria no baixo nivel de renda das populações urbanas, insuficiente para estimular a oferta e, desse modo, influenciar no redirecionamento do perfil produtivo em favor dos alimentos de consumo habitual.

Do exposto, pode-se concluir que os padrões de consumo estão intimamente dependentes da distribuição de renda. E o comportamento da economia, nas últimas décadas, alterou de maneira injusta a composição da renda entre os vários estratos sociais.

Em nosso país, a tendência concentradora é uma constante e acarreta reflexos éticos - a acentuação das desigualdades econômicas - a redução do acesso da população ao mercado, e políticos - o aumento da pobreza absoluta. Refere Munhoz ${ }^{41}$ que "o fenômeno da concentração de renda é irreversível numa economia de mercado e, frente à impossibilidade de reversão, pode e deve ser contido, reequilibrado, pela ação corre tiva do Estado".

Os dados disponíveis denunciam umą ampla disparidade na apropriação das rendas nacionais: em 1983, os $40 \%$ mais pobres participavam.de apenas $9 \%$ da renda global; os $50 \%$ da população na faixa de renda intermediária detinham $44 \%$; e os $10 \%$ ricos se aproximavam de $47 \%$ (nesse grupo 
situam-se os $5 \%$ mais ricos com $34 \%$ da renda do pais). Adverte Munhoz que as tendências observadas deixam de revelar toda a dramaticidade dos contingentes marginaliza. dos, ao não levar em conta o aumento da população urbana provocado pelo êxodo rural. Sabendo-se que o crescimento populacional urbano atinge a taxa de $5,6 \%$ ao ano, é possível estimar o avultado número de pessoas que deixam a vida rural. Outrossim, devemos considerar que essas disparidades se acentuam quando analisadas comparativamente às grandes regiōes: a região Nordeste é a mais penalizada. É, sem dúvida, um grande desafio à reversão dessa tendência concentracionista em proveito das regiōes mais atrasadas.

Esse perfil distributivo da renda implica em limitações quantitativas do consumo de alimentos, concorrendo para o aspecto essencialmente limitante da dieta do brasileiro, que é a restrịção calórica: $67 \%$ da população apresentam défícit energético e $17 \%$ um déficit energético diário superior a $400 \mathrm{kcal}$. (ENDEF).

No atinente ao padrão qualitativo da dieta, está representado por oito alimentos básicos - carnes, óleos, feijão, arroz, açúcar, trigo - que são, de modo geral, consumidos em todas as regiões (Tabela 5) e, praticamente, por todos os grupos sociais, ocupando as 5 primeiras posições como fontes de calorias e proteínas. No Norte e no Nordeste aparece a farinha de mandioca e na Amazônia e Centro-Oeste, $o$ peixe, como fontes calórica e protéica, respectivamente. São exceções mais de natureza ambiental do que cultural. Em decorrência da retirada do subsídio ao trigo (para uma inflação de $126,8 \%$ de janeiro a junho, o pão subiu $205 \%$ e o leite 436\%), gênero que, à vista da Tabela 5, é uma importante fonte protéica e energética, mormente para os segmentos de baixa renda, está prevista uma redução de consumo, em função da perda do poder aquisitivo da população.

Incontestavelmente, pães, massas e biscoitos são muito utilizados por essas populações e para diminuir o impacto negativo no consumo, com reflexos prováveis no estado nutricional, há notícias de que o ITAL, da UNICAMP, está experimentando a adição de $25 \%$ de farinha de milho integral desengordurada à de trigo. Há alguns anos o INAN testou exitosamente a adiçāo de farinha de soja, mas a obrigatoriedade da mistura não obteve a acolhida dos escalōes decisórios, apesar das vantagens economicas e nutricionais.

Aliás, em termos de consumo, a maior preocupação deve ser com o ganho real do salário mínimo. Agora, o salário mínimo congelado é o mais baixo de toda história e sem o gatilho haverá perda de 38\% (DIEESE). Em junho, a compra da cesta básica, calculada pela SUNAB, requeria de um assalariado-mínimo 205 horas de trabalho. 
DEBATE

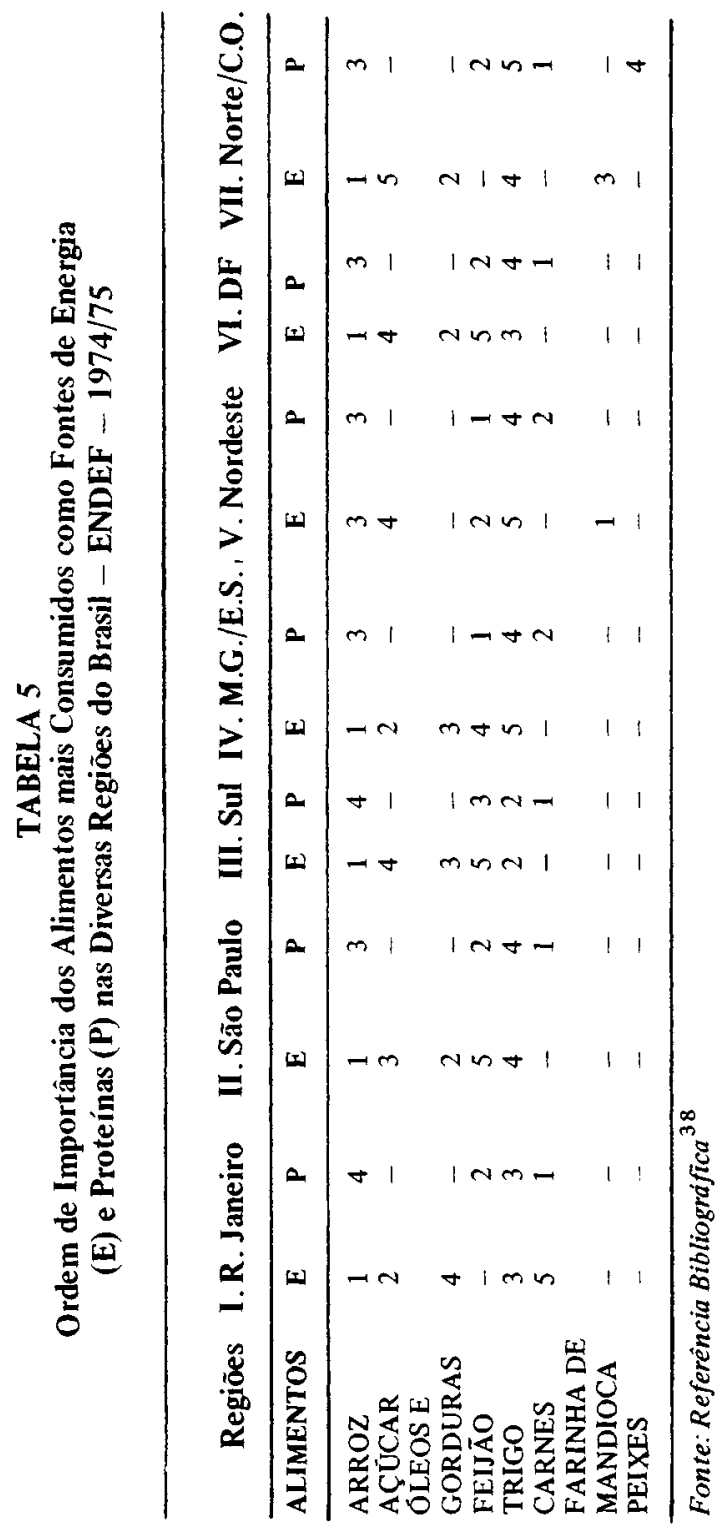


Pelo visto, estamos seguindo à risca o receituário do FMI, com a adoção de um Plano (Bresser) onde se misturam, na percepção do articulista da Revista VEJA (17.06. 87), o certo, o provável e o possivel. O certo reflete-se na mais concreta de todas as medidas - o congelamento de salários com a supressão do gatilho e substituição por "uma fórmula que poderá patrocinar o maior confisco salarial dos últimos trinta anos". Também é certa uma maior arrecadação, com o reajuste das tarifas de serviços públicos e do preço do aço e combustíveis acima da inflação. O provável é a contenção dos preços, pois está sendo praticado um "congelamento flexível". O possível é a redução do déficit público, uma vez que cortaram somente as obras futuras. Acrescente-se uma política cambial estimuladora da expansão de produtos exportáveis.

Estas considerações apontam para o agravamento do quadro estrutural da sociedade, indicativo da persistência das desigualdades de participação de seus membros no processo de produção e, em especial, de usufruto dos bens e serviços produzidos.

As restrições alimentares e as deficiências nutritivas, associadas aos problemas de saúde, radicam-se nesse contexto e explicam-se, basilarmente, pelo estado de pobreza a que se acham expostas parcelas ponderáveis da população brasileira.

Embora as familias pobres e ricas, sob o ponto de vista do aporte alimentar, disponham de um elenco comum de alimentos que fornecem, basicamente, calorias e proteínas, a quantidade consumida destes e de outros produtos ricos em nutrientes importantes como o ferro e a vitamina A, são bem diferentes. Também são muito diferentes, sob o prisma da utilização biológica dos nutrientes, porque a natureza e a intensidade dos agravos patológicos, assim como o aces. so aos serviços de saúde, são distintos.

Cabe aduzir que a desnutrição energético-protéica, a anemia e a hipovitaminose $\mathrm{A}$ comumente coexistem numa mesma criança e uma melhor compreensão dessa problemática exige também aferir as práticas do aleitamento ma. terno e do desmame adequado. Estas práticas têm implica. ções no estado nutricional e na própria condição de saúde da criança, seja pela redução do aporte de nutrientes na vigência da alimentação substitutiva, seja pelas características protetoras do lcite materno, especialmente em relação a processos infecciosos intestinais.

Além das intercorrên cias patológicas, sobretudo infecciosas (particularmente as doenças respiratórias agudas e as diarréias), fatores fisiológicos como a gestação e a lactação, em virtude das maiores exigências metabólicas, podem comprometer o estado de nutrição. 
0 sinergismo entre desnutrição e infecção está bem avaliado e o controle dessa associação binomial representa, indubitavelmente, a grande conquista no campo da saúde coletiva dos povos subdesenvolvidos. Especula-se que os avanços mais rápidos no controle da desnutrição seriam estrategicamente alcançados mediante o combate aos agravos infecciosos ${ }^{42}, 43$

0 importante a deduzir destas colocações é que o estado nutricional se define no microambiente, a nível familiar, e que o consumo de alimentos, embora condição necessária, nem sempre é suficiente para definir um bom estado nutricional. Isto porque a nutrição adequada, apesar de depender do valor da dieta, tem muito a ver com as doenças que, sobremaneira em crianças, podem afetar substancialmente a utilização de energia e nutrientes a nível celular.

Torna-se pertinente abordar um aspecto usualmente levantado, que é a racionalidade econômica nas familias de baixa renda, no que tange à compra de alimentos. Alves ${ }^{44}$, comparando famílias nutricionalmente adequadas com familias carentes, evidenciou que estas últimas escolhem e compram seus alimentos de maneira tão eficiente quanto as primeiras. Ao mesmo resultado chegou Rosenberg ${ }^{45}$, mostrando que as familias pobres provaram ser racionais na escolha de suas dietas, na medida em que realizam seus gastos tendo em vista as características nutritivas dos alimentos. E também Alves e Vieira ${ }^{46}$, ao analisarem orçamentos familiares na cidade de São Paulo, demonstraram que "existe uma grande racionalidade por parte da população de baixa renda em relação aos gastos com alimenta. ção".

Outra significativa dedução é que, independendo das regiões e da condição econômica, há uma concordância de consumo nos itens alimentares. Um conjunto de sete alimentos compõe, em todos os espaços geoeconômicos do país, os cinco primeiros lugares na formação da receita energética da população. E seis alimentos cobrem as cinco primeiras posições como fonte de proteinas.

Fica clara, portanto, a relativa homogeneidade do espaço alimentar brasileiro e a indicação preliminar de que a chave do problema, explicativa da distribuição geográfica da desnutrição, não se encontra na diversidade de hábitos alimentares, mas sim no quantitativo do consumo.

Por conseguinte, o que de fato prevalece é o critério do ajuste do orçamento, às custas de redução quantitativa dos alimentos mais caros e, às vezes, até mesmo dos mais baratos. Assim, a população mais pobre participa, efetivamente, dos hábitos alimentares de sua região, não 
possuindo um perfil alimentar qualitativamente próprio da "subcultura da pobreza".

Cumpre destacar, por uma questão de coerência da tese que estamos defendendo, o papel que a renda da população assume, na explicação dos ajustes que se processam na estrutura do consumo de alimentos, refletindo-se nos orçamentos familiares de forma bastante variável, podendo ir de menos de $10 \%$ na classe mais rica até mais de $70 \%$, na mais pobre.

Em época de crise - e nela estamos mergulhados - o consumidor é levado a restringir os gastos e geralmente opta pela redução das despesas supérfluas, chegando também a cortar os encargos considerados de maior necessidade. Assim, inicia-se um movimento de seleção de alimentos para consumo que obedece a uma lógica ditada, de um lado, pela necessidade de economizar e, de outro, para conseguir evitar a desnutrição e a fome.

Finalmente, cabe um alerta - a maior demanda por alimentos básicos vem acompanhada por um crescimento rápido de preços. Caso esta tendència seja mantida, estes alimentos poderâo, num futuro próximo, compor - elenco de produtos pouco acessiveis ao consumidor de menor renda, só the restando diminuir, cada vez mais, as quantidades, com agravamento do seu estado nutricional.

\section{3 - OS CAMINHOS DA SOLUÇÃO}

A análise da problemática alimentar e nutricional para controle efetivo dos problemas deve compreender, portanto, os dois niveis anteriormente enfocados:

- o nivel microeconómico - envolve os fatores estruturais, aponta para medidas de longo prazo, de molde a assegurar uma oferta qualitativa e quantitativa de alimentos, em função das necessidades nutricionais da população;

- o nível macroeconômico - abrange os fatores do microambiente, confere elevado peso à demanda, que se faz de modo desigual em virtude, predominantemente, do poder de compra do consumidor, e considera a influência dos fatores ocupacionais, fisiológicos e sobre tudo patológicos.

$\dot{E}$ imprescindivel ter em mente que estes setores se complementam, mutuamente se reforçam e consubstanciam a definição de uma política integrada de desenvolvimento econômico e social.

As doenças carenciais não têm uma distribuição aleatória na população. Há um risco de ocorrência que pode ser 
estimado ou previsto em face de determinadas variáveis. Além dos aspectos relativos à oferta e demanda de alimentos, no caso brasileiro faz-se mister chamar a atenção para alguns condicionamentos que in terferem na probabilidade do aparecimento da desnutrição: o predominio de populações jovens ( $70 \%$ no grupo materno-infantil), com elevado padrão reprodutivo, prole numerosa. franco deseauilibrio na relação entre pessoas economicamente ativas e dependentes, gestações em menores de 20 anos, ou inversamente, em maiores de 35 anos. No atinente à massa trabalhadora, o mais comum é exercer suas atividades sob condições insalubres e, principalmente, às custas de alto dispêndio de energia fisiológica, decorrente do trabalho muscular intenso.

Na precipitação ou agravamento dos problemas nutricionais está sempre agregado um componente infeccioso, cuja atuação se processa por mecanismos, múltiplos, encadeados e sinérgicos: redução do apetite, digestão incompleta, prejuízos de absorçâo, aumento das necessidades (como nos processos febris).

Admite-se que em nenhum outro exemplo de doenças humanas esteja o caráter multifatorial de sua explicação estruturalmente tão presente. Por isso a solução consagra uma concepção globalista e reclama a mobilização consciente e integral de todos os setores, proposta que se traduz, doutrinária e pragmaticamente, na definição e implementação de um modelo sócioeconômico isento de distorções que possam gerar os desequilibrios alimentares e nutricionais. Isto significa desenvolvimento pleno, pois assinala Singer 4 "o mais provável é que a pobreza e a desnutrição sejam fruto da falta de desenvolvimento, ou seja, do fato de ele ser parcial e incompleto nos países que apenas começaram a realizá-lo" e "o desenvolvimento capitalista é parcial, incorporando apenas uma fração da sociedade, enquanto uma outra parte vive, por assim dizer,

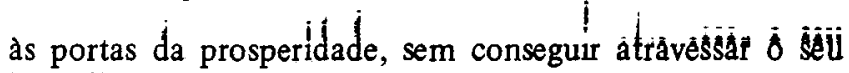
limiar".

Evidentemente, os problemas estruturais que desfiguram o processo de desenvolvimento econômico-social não constituem peculiaridade do nosso pais, pois fazem parte de um questionamento universal, válido, em especial, para as nações em fase de desenvolvimento. Porém válido, igualmente, para os países desenvolvidos e suas relações políticas, econômicas, culturais e até mesmo éticas com o mundo em desenvolvimento.

No combate à desnutrição não nos devemos mover apenas pelas razôes humanitárias, para mitigar o sofrimento das vítimas; a razão maior deve ser impedir o desperdício de re- 
cursos humanos ou, em linguagem econômica, do capital humano.

Isto porque o desenvolvimento é uma resultante da intervenção humana. A aplicação da tecnologia e o uso produtivo do capital e dos recursos naturais dependem do homem - como agente e como beneficiário de todo o processo.

Daí a nossa preocupação com as políticas de ajustes que, a exemplo da adotada agora, objetivam reduzir a inflação e restabelecer o crescimento econômico por meio de medidas cujos custos estão recaindo fortemente sobre os mais pobres - da cidade e do campo.

Impõe-se, como diz Lechtig $^{48}$, uma abordagem mais ampla da política de ajuste pois não basta uma postura humanitária, mas sim um erro econômico elementar: "Se o objetivo das políticas de ajuste é lançar as bases para o crescimento contínuo da economia a longo prazo, fica sem sentido ignorar as necessidades mais fundamentais da população envolvida no processo nutrição, saúde, educação". E lutar por níveis satisfatórios de emprego e salários.

É necessário, sem prejuízo das intervençōes de curto prazo que possam ser aplicadas - e as ações integradas de saúde e nutrição constituem estratégia prioritária - um compromisso mais vigoroso com as transformações das estruturas sociais e diretrizes econômicas. Seriam alternativas nacionais de ajuste que não dispensam, ao contrário, têm seu êxito umbilicalmente dependente da adoção urgente e real de alternativas internacionais de ajustamento quanto a três sérios entraves: remover o protecionismo alfandegário que dificulta as nossas exportações de bens manufaturados; obter preços mais compensadores para os nossos principais produtos primários de exportação; e certamente 0 grande estrangulamento - a divida externa, exigindo maiores prazos e menores taxas de juros e "spreads", condições de pagamento que não impliquem em sacrifíciọ.

E

claro que essa orientação passa, obrigatoriamente, pelo crivo e ação de duas instâncias: a sociedade, a quem cabe estabelecer o ritmo, a profundidade e a direção das mudanças; e o Estado, no papel de regulador e de indutor, participando concretamente da atividade econômica.

Em vista da forte influência que têm os fatores econômicos na desnutrição, diz Musgrove ${ }^{49}$, "os desafios são como desenhar a ajuda econômica, segundo os beneficiários podem ou não ser atingidos pelo crescimento econômico e o melhoramento da distribuição de renda, e como combinar, efetivamente, as mudanças econômicas com as intervenções dirigidas aos demais determinantes da desnutrição, os fatores não-econômicos, biológicos e culturais'.

Estamos côncios de que as soluções não constituem mistério, todavia, o enfrentamento desta realidade representa 
uma reorientação revolucionária. Enfim, o que se almeja é a harmonia le propósitos de toda a sociedade, em prol de novos padrc: de saúde e bem-estar, compatíveis com o ideal humanis: do desenvolvimento; é estabelecer uma sonvivência solic 'a que promova a qualidade de vida coletiva ${ }^{50}$.

Nessa ordem de idéias julgamos absolutamente pertinente recordar uma exortação que continua bem válida: "De nada valem medidas tímidas ou de contemporização. É preziso que se interprete a situação como se estivesse em risco a própria soberania nacional. Que se unam todas as forças $\geq$ que se envidem todos os meios na luta contra a mais vergonhosa de todas as síndromes: a criança faminta". 51

\section{REFERÊNCIAS BIBLIOGRÁFICAS}

1. CASTRO J. - Geopolítica da Fome. Ed. Casa do Estudante do Brasil, Rio, 1954 (3ạ ed.).

2. 1984 (10? ed.).

3. ABREU. M. P. - Texto para discussão n? 127 - Política Social no Brasil: a Relevância dos Parađigmas Históricos e Comparativos. PUC, Rio de Janeiro, 1987.

4. CHAVES, N. - Nutrição, Criança e Vida. Recife, Massangana, 1982.

5. INTERDEPARTMENTAL Committee on Nutrition for National Development. Northeast Brazil, Nutrition Survey, march/ may, 1963. Washington, 1965.

6. PINO, P. et alij. - Estado nutricional do adulto de área rurat do Nordeste. Recife, Universidade Federal de Pernambuco, 1984.

7. CIARI JUNIOR, C. et alii. Relaçāo e peso da criança ao nascer, altura materna, idade gestacional e restriçâo alimentar em gestantes normais. Revista de Saúde Pública, São Paulo 9(1): 33-42, 1975.

8. BATISTA FILHO, M. e AMIGO, H. - Epidemiologia das principais endemios carenciais no Brasil. Seminário sobre Prioridades de Pesquisas Aplicadas ao Planejamento da Nutrição Humana. CNPq, Brasília, 1982.

9. FUNDO das Naçōes Unidas para a Infância e Fundaçāo Instituto Brasileiro de Geografia e Estatística. Perfil Estatistico de Crianças e Mães no Brasil, aspectos nutricionais, 1974-1975, Rio de Janeiro, 1982.

10. BATISTA FILHO, M. - O Nordeste Brasileiro no Contexto Nacional: seus problemas nutricionais, seus programas de nutrição. Anais do II Encontro de Ciência e Tecnologia de Alimentos, Rio de Janeiro, 1984.

11. BENFAM - Pesquisa Nacional de Saúde Materno-Infantil e Planejamento Familiar. Rio de Janeiro, 1986.

12. ARRUDA, B.K.G. - Nordeste: políticas e estratégias em alimentaçăo e nutrição. Boletim sobre População, Emprego e Renda no Nordeste, vol. 4, n? 2/3, maio/dez, 1985.

13. MONTEIRO, C.A. et al. Estudo das Condiçōes de Saúde das Crianças do Município de São Paulo, S.P. - 1984-1985, II Antropometria Nutricional. Revista de Saúde Pública, São Paulo, 20:446-53, 1986. 
14. AFLIÇÃO SOB MEDIDA. ISTO E, 27/05/1987, São Paulo.

15. BATISTA FILHO, M. et al. - Estado nutricional de pré-escolares de comunidades rurais do Nordeste brasileiro. Rev. Bras. Med. vol. 42, no 7, julho de 1985 .

16. LIRA, P.J.C. et al. - Estadó Nutricional de Crianças menores de seis anos, segundo a posse da terra, em áreas rurais do Estado de Pernambuco, Nordeste do Brasil. Archivos Latinoamericanos de Nutrición, vol. XXXV (Junio, 1985) n? 2.

17. OLIVEIRA" J.E.D. et al. - "Boias-Frias". Realidade Brasileira. ACIESP, São Paulo, 1981.

18. SANTOS, I. et alii. - Xerophthalmis in the state of Paraiba, northeast of Brazil. American Journal of Clinical Nutrition. Maryland (28):202-208, 1975.

19. BRITO, D. - Estado Nutricional de Escolares de um Bairro do Recife. Recife, Univ. Fed. de Pernambuco, 1982.

20. BATISTA FILHO, M. e TORRES, M.A.A. - Acesso à terra e estado nutricional de crianças menores de 5 anos no semiárido nordestino. Revista Pernambucana de Desenvolvimento, Recife (3/4), 1982.

21. RONCADA, M. J.e WILSON, D. - Hipovitaminose A em filhos de migrantes em trânsito pela Central de Triagem e Encaminhamento (CETREN), na capital do Estado de São Paulo - estudo clínico-bioquímico. Revista de Saúde Pública, São Paulo, 12(3):345-350, set, 1978.

22. ARAUJO, R.L. - Diagnóstico da Situação da Hipovitaminose A e Anemia Nutricional na população do Vale do Jequitinhonha, Minas Gerais, Belo Horizonte, 1982.

23. LIRA, P.J.C. et al. - Estado Nutricional de Crianças menores de seis anos, segundo a posse da terra, em áreas rurais do Estado de Pernambuco, Nordeste do Brasil. Archivos Latinoamericanos de Nutrición, vol. XXXV (Junio, 1985), n? 2.

24. BATISTA FILHO, M. et al. - Anemia em adolescentes gestantes no Brasil. ENSP - FIOCRUZ, Rio de Janeiro, 1987

25. SHRIMPTON, R. et alii. - Epidemiologia das principais carências nutricionais no Brasil. In: $\mathrm{CNPq}$ - Prioridades de pesquisas aplicadas ao planejamento da Nutrição Humana. Brasília, 1982.

26. SALZANO, A.C. - Pesquisa Nutricional em trés áreas fisiografi. cas do Estado de Pernambuco, Recife, INUFPE/SUDENE, 1975.

27. SALZANO, A.C. et alii. - Prevalência de anemia no ciclo gestacional em dois Estados do Nordeste brasileiro - Pefnambuco e Paraíba. Revista Brasileira de Pesquisas Médicas e Biológicas. São Paulo, 13 (4/6); 211-214, 1980.

28. SALZANO, A.C. et al. - Anemias em criancas de dois serviços de saúde do Recife, PE (Brasil). Rev. Saúde Pub., São Paulo, 19:499-507, 1985.

29. SZARFAC, S. C. - Prevalência de anemia nutricional entre gestantes matriculadas em Centros de Saúde do Estado de São Paulo. São Paulo, Faculdade de Saúde Pública, USP, 1983.

30. LIRA, P.J.C. et al. - Estado Nutricional de Crianças Menores de seis anos, segundo a posse da terra, em áreas rurais do Estado de Pernambuco, Nordeste do Brasil. Archivos Latinoa. mericanos de Nutrición, vol. XXXV (Junio, 1985), n? 2.

31. ARRUDA, I. K. G. - Anemia em gestantes atendidas em serviços de saúde do Recife, Relatório de trabalho. Departamento de Nutriçõo, UFPE, Recife, 1979.

32. MEDEIROS NETO, A.- Bócio Endêmico, levantamento de sua prevalência por microrregiōes homogêneas. Revista Brasileira de Malariologia e Doenças Tropicais. Brasília, (1/4), 1978. 
33. BATISTA FILHO, M. - Nutrição, Alimentação e Agricultura no Nordeste Brasileiro - subsídios para uma política de extensão rural. EMBRATER/FAO, Brasilia, setembro de 1986.

34. MELO, F. H. - $\cap$ Problema Alimentar no Brasil. Paz e Terra, Rio de Janeiro, 1983.

35. - - A questão alimentar no Brasil sob o ponto de vista macroeconômico. In: Raizes da Fome - Vozes/FASE, Petrópolis, 1985.

36. BUainain, A. M. - Pequena Produção, Produçāo de Alimentos e Reforma Agrária no Brasil. Apresentado no Seminário sobre Economia e Nutrição, Brasilia, maio/1987.

37. KERTÉSZ, E. M. - O PRONAN como modelo de Política Social. Apresentado na VI Conferência Nacional de Saúde, Brasília, 1977.

38. ARRUDA, B. K. G. - Padrões e hábitos alimentares da população brasileira. Brasília, INAN, 1981.

39. CAMPINO, A.C.C. - Aspectos socioeconômicos da desnutrição no Brasil. Rev. Saúde Pública, S. Paulo, 30:83, 101, 1986.

40. MUSGROVE, P. - A Despesa Familiar e os Preços dos Alimentos como Determinantes do Consumo Alimentício no Nordeste Brasileiro. OPAS, Brasillia, agosto, 1986.

41. MUNHOZ, D.G. - Alternativas para uma Política de Rendas. UNB. Brasília, maio, 1987.

42. BECKER, R.A. e LECHTIG, A. - Brasil: evolução da mortalidade infantil no período 1977-1984. MS/SNABS/DNE, Brasilia, 1986.

43. ARRUDA, B.K.G. - Nutrição e Saúde - Justificativa e indicação de prioridades para a sua integração conceitual e programática. Recife, IMIP, set, 1986.

44. ALVES, E.L.G. -Nível Alimentar, Renda e Educação. Rev. ABIA /SAPRO, Campinas (30):17-45, maio, 1977.

45. ROSENBERG, E. O comportamento do consumidor em relação à nutrição. UNB. Brasília, 1974.

46. ALVES, E.L.G. e VIEIRA, J.L.T. - Evolução do padrão de consumo alimentar da população da cidade de São Paulo. Pesquisa, Planejamento e Economia, Rio de Janeiro 8(3):

272-750, dez, 1978.

47. SINGER, P. - Implicações da Desnutrição para o Desenvolvimento Econômico. Seminário sobre Economia e Nutrição, Brasília, maio de 1987.

48. LECHTIG, A. - Capital Humano: o fator mais importante nos países do Terceiro Mundo. Seminário sobre Economia e Nutrição, Brasília, maio de 1987.

49. MUSCROVE, $P$. - Os fatores econômicos no comportamento nutricional dos consumidores. Seminário sobre Economia e Nutrição, Brasília, maio de 1987.

50. ARRUDA, B.K.G. - A Política Alimentar e Nutricional Brasileira. VII Congresso Latino-Americano de Nutrição, Brasillia, nov, 1984

51. FIGUEIRA, F. - Desnutrição da Criança. Pediatria Moderna (Edição Especial), vol. IV, no 10, jan, 1970. 